\title{
Amphetamine-type substance related presentations to the Emergency Department Mental Health Team of a Local Health District in Australia
}

\begin{abstract}
Objectives: To identify the prevalence and profile of amphetamine type substance (ATS) related presentations to the Emergency Department Mental Health Team (EDMHT) of a Local Health District in Australia.
\end{abstract}

Methods: Data was collected from medical records of all ATS presentations to the EDMHT over a one-year period, between 1 January 2015 and 31 December 2015.

Results: Of all presentations referred to the EDMHT, $0.15 \%(\mathrm{~N}=189)$ were ATS related. Of these the majority were male, the average age was $32,19.0 \%$ engaged in intravenous drug use, some were aggressive and $15.9 \%$ required tranquilisation. The most common presenting issues were psychosis and suicidal threats, intent, and behaviour (including intentional overdose). Multiple comorbid conditions were identified. On discharge 34.4\% were admitted into a psychiatric hospital and $32.8 \%$ were referred to Community Mental health teams.

Conclusions: ATS users suffer from multiple comorbidities and pose a significant burden on emergency services.

Keywords: amphetamines, emergency department, mental health 
According to the 2010 Global Burden of disease study there were 17.2 million amphetamine dependent people world over, in 2010 (1), with this number rising significantly between 2002 and 2014, especially among young adults $(2,3)$. Australasia was identified as having the second highest amphetamine dependence, behind the Asian regions (1). Amphetamine-type substances (ATS) are stimulant drugs, with the most popular ones amongst recreational users including amphetamine, methamphetamine, phentermine, 3,4-methylenedioxyamphetamine (MDA), 3,4-methylenedioxymethamphetamine (MDMA) and 3,4-methylenedioxy-Nethylamphetamine (MDEA)(4). Stimulant use is associated with significant harms and comorbidities such as suicide attempts, homelessness, imprisonment, depression and anxiety (5). ATS users present a significant burden to hospital Emergency Departments (ED) (6); they present with a range of issues, particularly aggression and agitation, and tend to be less cooperative compared to other toxicology related presentations (7).

This study identified the prevalence and profile of ATS related presentations referred to the ED mental health team (EDMHT) of a Local Health District in Australia. ATS presentations are referred to the EDMHT from ED (usually from ED triage) if there are confirmed or suspected comorbid mental health concerns. The aim of this study was to gain insight into the burden of this population on the EDMHT so that appropriate interventions could be developed.

\section{Methods}

A retrospective file review was undertaken, of all ATS related presentations to the EDMHT of the Central Coast Local Health District (CCLHD), over a one-year period, between 1 January 2015 and 31 December 2015. CCLHD is situated in a peri-urban area of New South 
Wales, Australia, and includes two EDs situated at Gosford and Wyong hospitals, serving a population of 333,119, with a combined annual census of 124,904 in 2015. In ED, cases of substance use are referred to the EDMHT for review when mental health issues are identified at triage or by ED staff. At each ED there is an EDMHT available 24 hours a day to provide specialised management alongside medical care in ED (8). The EDMHT maintains a log of patients referred for drug related presentations, from which ATS users for inclusion were identified. All presentations to the EDMHT determined to be related to recent ATS use were included. ATS use was self-reported in most cases on history taking (but some were identified on urine drug screen or on collecting collateral history). The first author examined the electronical medical records (eMR) of identified patients and extracted data in relation to presenting issue, sex, age, legal status, accommodation status, criminal history, all tranquiliser use in ED, opioid substitution therapy, length of stay for those hospitalised, seclusion and restraint use, comorbid disorders (in relation to the current presentation), current comorbid substances of abuse as recorded on that specific presentation (not the reason why they presented to ED), and discharge destination from ED. The collected data was pooled, entered into an Excel spreadsheet and IBM SPSS software was used for statistical analysis. Ethics approval was obtained from the Director of Clinical Governance in the CCLHD.

\section{Results}

There was a total of 189 ATS related presentations seen by the EDMHT. This is $0.15 \%$ of all ED presentations during that period (124,904 ED presentations), at a rate of 16 per month. The average age was 32 (minimum 17 maximum 59, SD 9.29 years), 85.2\% $(\mathrm{n}=161)$ were aged 40 and below, and $71.4 \%(n=135)$ were male. At presentation, $11.6 \%(n=22)$ were 
scheduled by a police officer and $3.7 \%(n=7)$ were scheduled by an ambulance officer under the NSW Mental Health Act 2007 while $84.7 \%(n=160)$ were voluntary presentations. A criminal history (conviction by a court of law or police charges as self-reported or reported from collateral sources of information during that specific presentation to ED) was identified in $31.2 \%(\mathrm{n}=59)$ and $12.7 \%(\mathrm{n}=24)$ were homeless. Some ATS users were on opioid substitution therapy, with $6.9 \%(n=13)$ on methadone and $2.6 \%(n=5)$ on Suboxone. Table 1 , lists the presenting issues.

\section{Insert Table 1}

As per Table 2 and 3, patients presented with a range of comorbid mental and physical health concerns and substances of abuse.

\section{Insert Table 2}

\section{Insert Table 3}

Tranquilisers were used in ED in at least $15.9 \%(n=30)$ presentations and $14.8 \%(n=28)$ required parenteral sedation (see table 4).

\section{Insert Table 4}


Table 5 outlines discharge destinations from ED (after assessment by EDMHT). For those admitted into a psychiatric hospital $(34.4 \%, \mathrm{n}=65)$, the average length of stay was 12.2 days (minimum 1 maximum 88, SD 16.3 days) and for those admitted into a drug and alcohol unit $(3.2 \%, \mathrm{n}=6)$ the average length of stay was 3 days (minimum 1 maximum 5, SD 1.6 days). The rates of seclusion and restraint among ATS users admitted into a psychiatric hospital were $12.3 \%(\mathrm{n}=8)$ and $10.8 \%(\mathrm{n}=7)$ respectively.

\section{Insert Table 5}

\section{Discussion}

ATS users seen by EDMHT constituted $0.15 \%$ of all presentation to ED, which is lower than rates reported in the literature of around $1 \%(7,9)$. This is most likely because not all ATS presentations to the ED are referred to the EDMHT. Our finding that most ATS presentations were male is consistent with previous research that indicates that at least two thirds of ATS users are male $(5,7)$. We found that users were relatively young (average age of 32 , with the majority under 40 ) which is also consistent with the literature $(2,9)$, and indicates a need for interventions specifically targeting males under the age of 40 . Almost a third (31.2\%) of presentations were identified as having a criminal history (any conviction or police arrest), which is comparable to other findings that show that $17.2 \%$ of ATS presentations had previously been jailed (5). Some of our presentations were homeless (12.2\%) compared to $21.9 \%$ reported by another Australian study (5).

Consistent with the existing literature, our study found that ATS presentations to the EDMHT occurred in the context of comorbid mental illness $(5,9)$. ATS related EDMHT presentations were most likely to occur in the context of suicidality or intentional overdose $(31.8 \%)$ and this is consistent with evidence that shows that people with stimulant use disorders report 
high rates of suicidality (5). The 2007 National Survey of Mental Health and Wellbeing found that $31.7 \%$ of respondents with a lifetime stimulant use disorder reported suicidal ideas (5). However, not all studies capture such high rates of suicidal ideation in this population; a Californian study identified only $10.5 \%$ of ATS users as suicidal (10), and an Australian study from Perth found that only $6.4 \%$ of amphetamine-related ED presentations were suicidal (9). While it is unclear why there is such variation between studies, it is likely that our approach where drug related ED presentations with identified mental health issues are assessed by a specialist mental health team is highly effective at identifying mental health concerns.

The prevalence of psychosis identified here $(34.4 \%)$ is similar, albeit a little higher, to findings reported in the literature of $27 \%$ (7) and $26 \%(11)$ and this could be due to our study examining patients referred to the EDMHT only. Our study reports relatively low rates of aggression in ATS ED presentations (12.2\%), at least in comparison to some of the literature. The rates of ATS user aggression in Australian EDs reported in the literature ranges from $8.3 \%$ in an ED in Perth (9) to $65.4 \%$ in a Melbourne ED (12). In terms of sedation, our finding that $15.9 \%$ of ATS presentations received tranquilisers (with $14.8 \%$ requiring parenteral tranquilisers) is low in comparison to $32 \%$ reported in the literature (9). We identified lower rates of intravenous drug use (19.0\%) than reported by other studies (71\%) (9).

A high proportion of ATS related presentations were admitted to either a mental health inpatient facility (34.4\%) or a drug and alcohol unit (3.2\%), and this is consistent with evidence from California that shows that $35.0 \%$ of ATS related ED presentations required admission in 2016 (10). More users were referred for follow up by community mental health teams (CMHT) than follow up by a general practitioner (GP) $(1.1 \%)$ or by community drug and alcohol services. Follow up by mental health services is based on a more assertive 
approach compared to the latter where patients have to proactively contact a GP or drug and alcohol services. As there is no means of ensuring patients will comply with the latter, a high rate of referral to CMHT may ensure greater patient safety and better outcomes. Since users suffer from various comorbidities(10), this identifies missed opportunities to engage them at a primary health level. However, it is also possible that most ATS users do not have identifiable GPs and other clinicians/CMHT can still refer patients to GPs and drug and alcohol services on follow up.

While our study contributes to the literature in relation to the profile of ATS presentations to the EDMHT, a number of limitations need to be noted. The data was collected by various clinicians working under the fluctuating pressures of the ED, ATS was self-reported in most cases and users with acute medical or surgical issues were not referred to the EDMHT thereby creating potential information bias. The data is limited to one Local Health District of NSW and as such limited in the extent to which it can be generalised. There may also be confounding factors that have not been controlled for, e.g. presentations of psychosis/suicide may not necessarily be related to ATS use.

\section{Conclusion}

Our study outlines the profile of ATS related presentations to the EDMHT of a Local Health District in a peri-urban area of NSW and contributes to a body of literature that highlights the burden of ATS presentations. High rates of psychosis, suicidality, intravenous drug use, criminal history, Hepatitis C, comorbid substance use and psychiatric hospitalisation were observed. 
We are grateful to Associate Professors Loyola Maclean and Louise Nash, Dr Andrew Walker and Dr Kathryn Broadhouse for their assistance.

\section{Disclosure}

The authors declare that there is no conflict of interest.

\section{Funding}

This research received no specific grant from any funding agency in the public, commercial, or not-for-profit sectors. 
Table 1. Presenting complaint of ATS users at presentation to EDMHT*

\begin{tabular}{|l|l|}
\hline Variable & Number \\
\hline Psychosis & $34.4 \%(\mathrm{n}=65)$ \\
\hline Suicidal & $27.0 \%(\mathrm{n}=51)$ \\
\hline Aggression & $12.2 \%(\mathrm{n}=23)$ \\
\hline Other complaints & $6.3 \%(\mathrm{n}=12)$ \\
\hline Intentional overdose & $4.8 \%(\mathrm{n}=9)$ \\
\hline Intoxication & \\
\hline Anxious & $4.2 \%(\mathrm{n}=8)$ \\
\hline Depression & $3.2 \%(\mathrm{n}=6)$ \\
\hline Self-inflicted lacerations & $2.6 \%(\mathrm{n}=5)$ \\
\hline Homicidal & $2.1 \%(\mathrm{n}=4)$ \\
\hline & \\
\hline & \\
\hline & \\
\hline & \\
\hline & \\
\hline & \\
\hline & \\
\hline & \\
\hline
\end{tabular}




\begin{tabular}{|l|l|}
\hline Poor sleep & $0.5 \%(\mathrm{n}=1)$ \\
\hline Failure to cope & $0.5 \%(\mathrm{n}=1)$ \\
\hline
\end{tabular}

*identified as the presenting complaint on assessment by the EDMHT.

Table 2. Primary comorbid disorders* in ATS users relevant to the current presentation

\begin{tabular}{|l|l|}
\hline Comorbidity & Number \\
\hline Intravenous drug use (IVDU) & $19.0 \%(\mathrm{n}=36)$ \\
\hline Personality disorder & $14.8 \%(\mathrm{n}=28)$ \\
\hline Hepatitis C & $14.3 \%(\mathrm{n}=27)$ \\
\hline Schizophrenia & $9.5 \%(\mathrm{n}=18)$ \\
\hline Depression & $9.0 \%(\mathrm{n}=17)$ \\
\hline Attention-Deficit Hyperactivity Disorder & $9.0 \%(\mathrm{n}=17)$ \\
\hline (ADHD) & \\
\hline Bipolar disorder & $6.3 \%(\mathrm{n}=12)$ \\
\hline Anxiety & $4.8 \%(\mathrm{n}=9)$ \\
\hline Chronic pain & \\
\hline
\end{tabular}




\begin{tabular}{|l|l|}
\hline Seizures/epilepsy & $3.2 \%(\mathrm{n}=6)$ \\
\hline Schizoaffective disorder & $2.6 \%(\mathrm{n}=5)$ \\
\hline Oppositional defiant disorder (ODD) & $1.6 \%(\mathrm{n}=3)$ \\
\hline HIV & $0.5 \%(\mathrm{n}=1)$ \\
\hline Conduct disorder & $0.5 \%(\mathrm{n}=1)$ \\
\hline Gambling addiction & $0.5 \%(\mathrm{n}=1)$ \\
\hline Pornography addiction & $0.5 \%(\mathrm{n}=1)$ \\
\hline
\end{tabular}

*not the presenting complaint i.e. identified elsewhere on the electronic medical record. 
Table 3. Comorbid substances of abuse

\begin{tabular}{|l|l|}
\hline Substance of abuse & Number \\
\hline Cannabis & $51.3 \%(\mathrm{n}=97)$ \\
\hline Alcohol & $38.6 \%(\mathrm{n}=73)$ \\
\hline Tobacco & $28.6 \%(\mathrm{n}=54)$ \\
\hline Heroin & $9.0 \%(\mathrm{n}=17)$ \\
\hline Benzodiazepines & $7.9 \%(\mathrm{n}=15)$ \\
\hline Prescription opioids & $7.4 \%(\mathrm{n}=14)$ \\
\hline Cocaine & $2.6 \%(\mathrm{n}=5)$ \\
\hline Lysergic acid diethylamide (LSD) & $1.1 \%(\mathrm{n}=2)$ \\
\hline Methadone & $1.6 \%(\mathrm{n}=3)$ \\
\hline Pregabalin & \\
\hline & \\
\hline & \\
\hline & \\
\hline & \\
\hline & \\
\hline & \\
\hline & \\
\hline
\end{tabular}




\begin{tabular}{|l|l|}
\hline Testosterone & $1.1 \%(\mathrm{n}=2)$ \\
\hline y-hydroxybutyrate $(\mathrm{GHB})$ & $0.5 \%(\mathrm{n}=1)$ \\
\hline Ketamine & $0.5 \%(\mathrm{n}=1)$ \\
\hline Olanzapine & $0.5 \%(\mathrm{n}=1)$ \\
\hline Risperidone & $0.5 \%(\mathrm{n}=1)$ \\
\hline
\end{tabular}

\section{Table 4. Tranquiliser use in ED*}

\begin{tabular}{|l|l|}
\hline Benzodiazepine tranquiliser treatment in ED & $13.8 \%(\mathrm{n}=26) / 15.9 \%(\mathrm{n}=30)$ \\
\hline - parenteral/oral & \\
\hline parenteral/oral & \\
\hline
\end{tabular}

*Some patients received both oral and parenteral, or both benzodiazepines and antipsychotics tranquilisers. Tranquilisers were used to manage aggressive patients, but also to manage psychosis, anxiety, and suicidal patients. 
Table 5. Discharge destination from ED*

\begin{tabular}{|l|l|}
\hline Outcome & Number \\
\hline Psychiatric admission & $34.4 \%(\mathrm{n}=65)$ \\
\hline Adult community mental health team & $30.7 \%(\mathrm{n}=58)$ \\
\hline Outpatient drug and alcohol services & $11.6 \%(\mathrm{n}=22)$ \\
\hline No follow up arrangements documented & $6.9 \%(\mathrm{n}=13)$ \\
\hline Drug and alcohol admission & $3.2 \%(\mathrm{n}=6)$ \\
\hline Referred to other medical specialties & $3.2 \%(\mathrm{n}=6)$ \\
\hline Police custody & $3.2 \%(\mathrm{n}=6)$ \\
\hline Absconded from ED & $2.6 \%(\mathrm{n}=5)$ \\
\hline
\end{tabular}




\begin{tabular}{|l|l|}
\hline Youth community mental health team & $2.1 \%(\mathrm{n}=4)$ \\
\hline GP & $1.1 \%(\mathrm{n}=2)$ \\
\hline Social worker & $1.1 \%(\mathrm{n}=2)$ \\
\hline
\end{tabular}

*after assessment by EDMHT. 


\section{References}

1. Degenhardt L, Baxter AJ, Lee YY, Hall W, Sara GE, Johns N, et al. The global epidemiology and burden of psychostimulant dependence: findings from the Global Burden of Disease Study 2010. Drug Alcohol Depend. 2014;137:36-47.

2. Degenhardt L, Larney S, Chan G, Dobbins T, Weier M, Roxburgh A, et al. Estimating the number of regular and dependent methamphetamine users in Australia, 2002-2014. Med J Aust. 2016;204(4):153.

3. Stafford J BL. $<$ Key findings from the 2014 Drug Illicit Drug Reporting System.pdf $>$. Proceedings of the 2014 National Drug Trends Conference. 2014.

4. Wozniak MK, Wiergowski M, Aszyk J, Kubica P, Namiesnik J, Biziuk M.

Application of gas chromatography-tandem mass spectrometry for the determination of amphetamine-type stimulants in blood and urine. J Pharm Biomed Anal. 2017;148:58-64. 5. Sara G, Burgess P, Harris M, Malhi GS, Whiteford H, Hall W. Stimulant use disorders: characteristics and comorbidity in an Australian population sample. Aust N Z J Psychiatry. 2012;46(12):1173-81.

6. Fulde GW, Forster SL. The impact of amphetamine-type stimulants on emergency services. Curr Opin Psychiatry. 2015;28(4):275-9.

7. Bunting PJ, Fulde GW, Forster SL. Comparison of crystalline methamphetamine ("ice") users and other patients with toxicology-related problems presenting to a hospital emergency department. Med J Aust. 2007;187(10):564-6.

8. Skopek MA, Francis JL. Presentations by ambulance under the NSW Mental Health Act to an emergency department with a 24-hour mental health team. Australas Psychiatry. 2016;24(5):445-8.

9. Gray SD, Fatovich DM, McCoubrie DL, Daly FF. Amphetamine-related presentations to an inner-city tertiary emergency department: a prospective evaluation. Med J Aust. 2007;186(7):336-9.

10. Richards JR, Hamidi S, Grant CD, Wang CG, Tabish N, Turnipseed SD, et al. Methamphetamine Use and Emergency Department Utilization: 20 Years Later. J Addict. 2017;2017:4050932.

11. Ridley K, Coleman M. The epidemiology of amphetamine type stimulant-related admissions in Albany, Western Australia: 2008-2013. Australas Psychiatry. 2015;23(3):2414.

12. Unadkat A, Subasinghe S, Harvey RJ, Castle DJ. Methamphetamine use in patients presenting to emergency departments and psychiatric inpatient facilities: what are the service implications? Australas Psychiatry. 2018:1039856218810155. 